\title{
EFFECT OF IODINE ON THE THYROID GLAND IN GRAVES' DISEASE WHEN GIVEN IN CONJUNCTION WITH THIOURACIL- A TWO-ACTION THEORY OF IODINE ${ }^{1}$
}

\author{
By RULON W. RAWSON,2 FRANCIS D. MOORE, WENDELL PEACOCK, \\ J. H. MEANS, OLIVER COPE, AND CHARLOTTE B. RIDDELL \\ (From the Thyroid Clinic of the Massachusetts General Hospital, Boston, and the Radioactivity Center \\ of the Department of Physics, Massachusetts Institute of Technology, Cambridge)
}

(Received for publication June 4, 1945)

The improvement observed in patients with Graves' disease following the administration of iodine is a phenomenon which has excited considerable speculation as to its mechanism.

Plummer (1) who introduced (or better, reintroduced) iodine in the therapy of Graves' disease, advanced a 2-product theory of thyroid secretion in that malady. His suggestion was that an incompletely iodinated hormone is secreted in Graves' disease which has toxic properties not possessed by the normal hormone. The improvement under iodine therapy he attributed to restoration of complete iodination of the hormone molecule.

In this clinic, studies have been in progress on the action of iodine in Graves' disease ever since Plummer's contribution in 1923. For his 2product theory, there has been found little if any convincing support, but his claims as to the benefit conferred by iodine in Graves' disease have been abundantly confirmed.

In contrast to Plummer's 2-product theory, we wish to suggest a theory that iodine has 2 quite distinct actions upon the thyroid, not only in Graves' disease, but perhaps under other circumstances as well.

The germ of a 2-action theory of iodine goes back a good many years in our clinic. For example, in 1929 (2), the following opinion was expressed: "We believe that for the present, at least, it will be wholesome for the profession to look upon the action of minute amounts of iodine in preventing endemic goiter as being in its nature very different from that of far larger quantities in bringing about detoxication in exophthalmic goiter."

\footnotetext{
1 Aided by grants from the Josiah Macy, Jr., Foundation, Parke-Davis Company, and an anonymous donor.

2 Henry P. Walcott Fellow, Harvard University.
}

The primordial rôle of iodine in thyroid economy is obviously that of supplying an ingredient essential to hormone synthesis. We may call this the "iodinating action." It has been estimated that in the healthy human this function can be served by as little as $0.075 \mathrm{mgm}$. of iodine per day. If an excess of iodine, that is to say, more than is necessary to serve the iodinating function, is administered to a normal person, it exerts no noteworthy effect. The thyroid traps the iodine needed and lets the rest go by to be excreted. If the quantity of iodine ingested is insufficient to fill the needs of the iodinating function, an iodinewant type of goiter develops.

The picture is very different in Graves' disease. Here the thyroid is rapidly utilizing available iodine in the manufacture of thyroid hormone and has an avidity for iodine which is about 2 to 3 times that of the normal human thyroid. In this disease when iodine is administered in adequate amounts involution of the thyroid and detoxication of the patient results. However, the dose of iodine necessary to produce this effect is $6.0 \mathrm{mgm}$. or more daily (3), an amount that is at least 80 times as great as the amount of iodine necessary to prevent the development of an iodine-want goiter. This action of iodine we can call the involuting action.

The manner in which this involuting action is produced has been obscure. Because of the similarity of the curves of the metabolic response to iodine in Graves' disease and of the thyroxine decay in the thyroidectomized subject, it was concluded that in Graves' disease the effect of a relatively large supply of iodine is to block the delivery of thyroid hormone from gland to body (4). Other workers have reached similar conclusions. Such an interruption of hormone output could be due to a cessation of hormone manu- 
facture or to some barrier to the escape of hormone from the gland. Certain observations (5) would support the latter. It was demonstrated that the total and thyroxine-like iodine of thyroids removed from thyrotoxic patients after iodine treatment were as great or greater than those observed in normal human thyroids in contrast to the low values observed in the thyroids of thyrotoxic patients who had had no iodine therapy.

The theory was advanced (6) that at least part of the action of iodine was to suppress the secretion of the thyroid-stimulating hormone of the pituitary. It was proposed that part of the action of iodine was to prevent the action of the thyrotropic hormone (7).

It has been suggested (8) that "the effect of iodine therapy is to favor the synthesis and deposition of thyroid hormone rather than its release." More recently this theory has been elaborated upon by an investigator who considers this the best explanation as to why iodine is beneficial in the treatment of Graves' disease (9). He suggests "that the gland is made to secrete internally into its follicles rather than externally into the blood stream. Thus iodide in excess," he suggests, "may be said to reverse the direction of flow of hormone."

In the light of the theory advanced by these investigators (8) it can be argued that what we have defined as separate actions of iodine are actually no more than 2 aspects of a single action. Such an argument can be refuted by separating the 2 actions. Such a separation involves the use of a goitrogenic drug like thiouracil. It has been demonstrated (10 to 13 ) that under sufficiently large and sustained dosage with this drug, utilization of iodine for hormone manufacture by the thyroid can be kept in abeyance. Under this treatment, the thyroid becomes hyperplastic due to pituitary stimulation, but still no thyroid hormone is synthesized because of the impediment to iodination exerted by the goitrogenic drug. Yet, if in Graves' disease while continuing the suppression of the iodinating action through the administration of thiouracil, iodine is given in addition, as the following observations demonstrate, involution of the thyroid can be induced. Thus, under these circumstances the iodinating action and the involuting action have been divorced.

\section{OBSERVATIONS, MATERIAL AND METHODS}

For the purpose of separating the iodinating and involuting actions of iodine, the following studies were made in 7 patients suffering from Graves' disease. In 4 patients the histology of the thyroid was studied in sections of biopsy specimens taken before any therapy, and also after a fall in the rate of metabolism to a standard level had been produced by the administration of thiouracil. These histologic specimens were compared with sections taken from several areas of the operatively-removed thyroids after continued thiouracil and added iodine treatment. In 3 other patients the histology of 1 biopsy specimen, taken from the thyroid after treatment with thiouracil had produced a fall in the rate of metabolism to a standard level, was compared with the microscopic picture of several histologic specimens taken from the operatively-removed thyroid after iodine had been added to the continued thiouracil treatment.

The urinary excretion of tracer doses of radioactive iodine was determined in 3 cases before beginning any form of treatment and in 6 cases after thiouracil treatment had caused a fall in the rate of metabolism to a standard level. Finally, the total iodine and the thyroglobulin iodine of each operatively-removed thyroid were determined.

All of the iodine administered to 1 patient, A. S., No. 24684, was labelled with radioactive iodine and thus a balance study was made. This patient was a 16-year-old female who suffered from a moderately severe Graves' disease. Her pretreatment basal metabolic rate level was plus 35. Before beginning treatment, she received 150 micrograms of iodine as sodium iodide labelled with 100 microcuries of 8-day half life radioactive iodine, and the urinary excretion of the labelled iodine was followed. Two days later a biopsy was taken from her thyroid. Following the biopsy thiouracil was administered, 0.2 gram every 6 hours. Her basal metabolic rate fell to a level of plus 10 in 8 days. On the eighth day of treatment, a second tracer dose of iodine was given, and another biopsy was taken from her thyroid on the tenth day. Following the second biopsy, thiouracil treatment was continued and $300 \mathrm{mgm}$. of iodine as sodium iodide were administered daily for 10 days until the thyroid was removed. The iodine was exhibited 1 hour after 10.2 -gram dose of thiouracil had been given. Each daily dose of iodine was labelled with 100 microcuries of 8-day half life radioactive iodine. All urine was collected and the iodine excreted was determined by measuring the radioactivity in the urine. The radioactivity contained in several specimens of the operatively-removed thyroid was also determined on alkaline digests of these samples.

The patients on whom these studies were made were all females varying in age from 16 to 37 years. All but 1 had a moderately severe thyrotoxicosis with pretreatment BMR levels which ranged between +20 and +55 . A. H., No. 25234, was only mildly thyrotoxic and probably not a good subject for this study. It is interesting to note, however, that her thyroid thyroglobulin iodine was quite low (see Table II). Only 2 of the patients, R. M., No. 


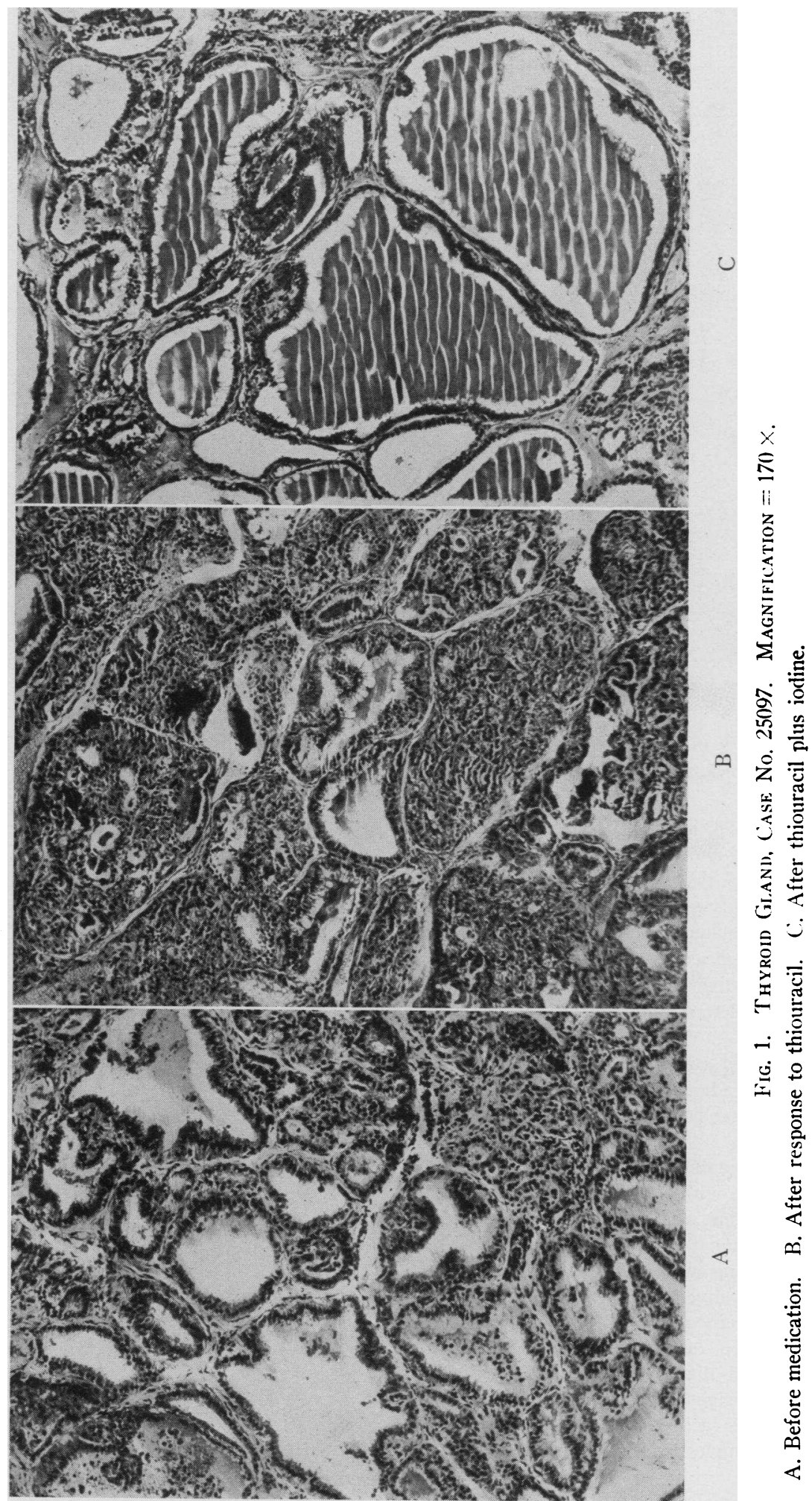




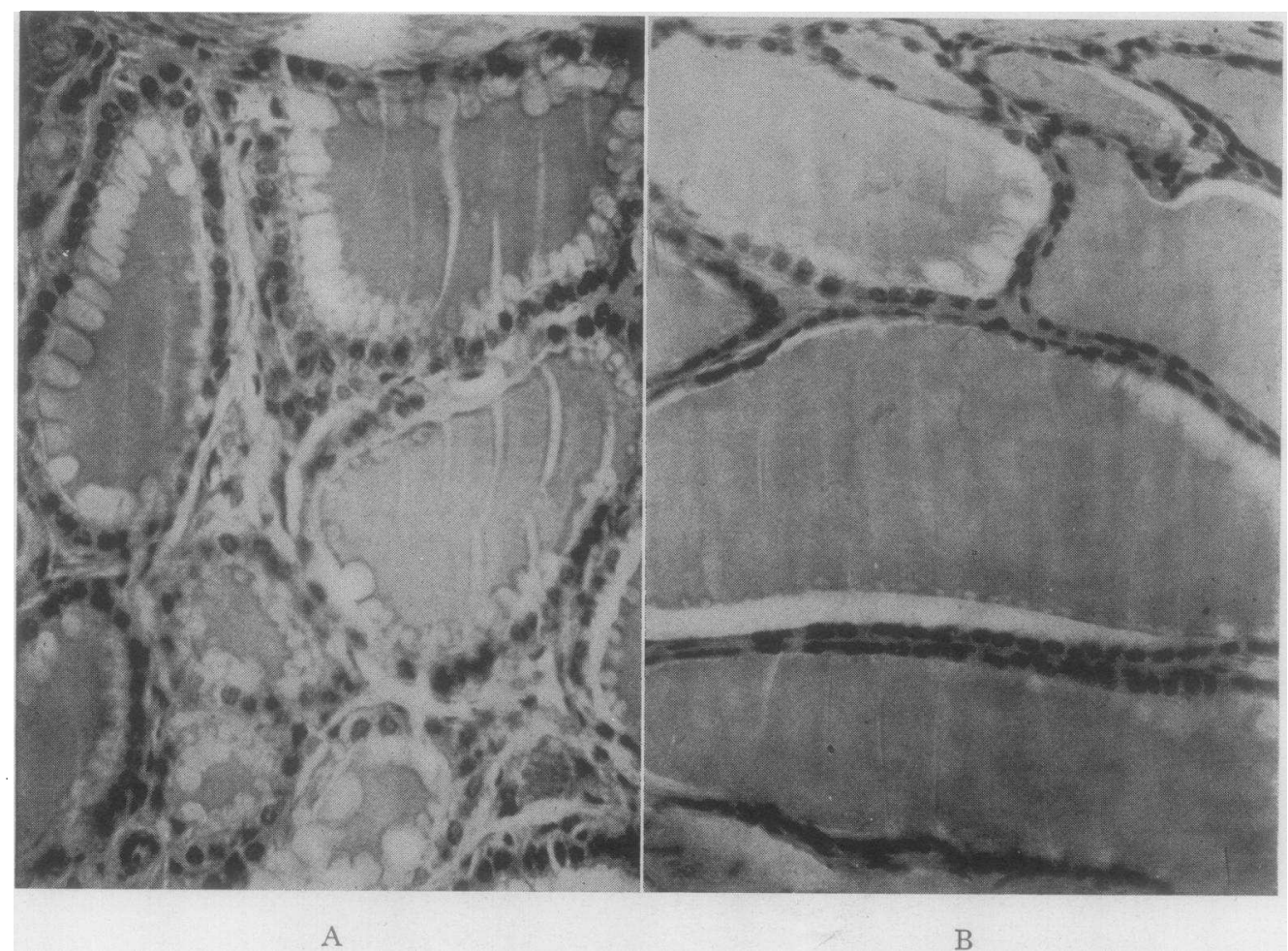

Fig. 2. Thyroid Gland, Case No. 25314. Magnification $=450 \times$.

A. After response to thiouracil. B. After thiouracil plus iodine treatment.

25314, and E. L., No. 25198, had had iodine in any form within 6 months before thiouracil treatment was begun.

The histologic studies of thyroid biopsy specimens and operatively-removed thyroids were compared quantitatively by determining the mean acinar cell height of each specimen. This was done by measuring under oil immersion the height of 1 representative cell from each of 100 successive acini and then determining the mean of each plotted curve.

The urinary excretion of radioactive iodine was determined by comparing the radioactivity in a measured sample of the urine with a standard taken from the original sample given the patient. The sample of radioactive iodine given the patient contained 100 microcuries of 8-day half life radioactive iodine with 150 micrograms of iodine as sodium iodide. All urine was collected and saved for 48 hours after administering the labelled iodine.

The thyroids after being weighed were minced in a Waring blender and then digested in $0.01 \mathrm{~N}$ sodium hydroxide and filtered through gauze. A sample was then removed for determination of total iodine and another sample was removed and dialysed. Thyroglobulin was then precipitated by lowering the $\mathrm{pH}$ to 5.4 to 5.6 with slowly added $0.1 \mathrm{~N}$ acetic acid. The iodine was determined in each of the 3 samples by the method of Astwood and Bissell (11).

The thiouracil was administered in 0.2 gram doses every 8 or every 6 hours throughout the period of study. Iodine was administered to all patients except A. S., No. 24684, as saturated potassium iodide $0.3 \mathrm{ml}$. (330 $\mathrm{mgm}$.) daily. The iodine was given 1 hour after one 0.2 -gram dose of thiouracil had been administered.

\section{RESULTS}

Mean acinar cell heights of thyroid parenchyma are given in Table I. These show in 4 cases,

TABLE I

Thyroid cell heights, before and during thiouracil treatment, and after thiouracil plus iodine treatment

\begin{tabular}{l|c|c|c|c}
\hline & & \multicolumn{3}{|c}{ Mean acinar cell height in micra } \\
\cline { 3 - 5 } Patient & Lab. no. & $\begin{array}{c}\text { At biopsy } \\
\text { before } \\
\text { any } \\
\text { treatment }\end{array}$ & $\begin{array}{c}\text { At biopsy } \\
\text { after } \\
\text { thiouracil } \\
\text { treatment }\end{array}$ & $\begin{array}{c}\text { At operation } \\
\text { after thiouracil } \\
\text { plus iodine } \\
\text { treatment }\end{array}$ \\
\hline C. T. & 24972 & $12.6 \pm 0.14^{*}$ & $13.9 \pm 0.14^{*}$ & $6.2 \pm 0.03^{*}$ \\
A. H. & 25234 & $11.1 \pm 0.13$ & $10.8 \pm 0.13$ & $7.4 \pm 0.05$ \\
H. M. & 25097 & $13.9 \pm 0.19$ & $14.3 \pm 0.15$ & $8.2 \pm 0.05$ \\
A. S. & 24684 & $15.3 \pm 0.14$ & $17.3 \pm 0.17$ & $10.3 \pm 0.07$ \\
E. L. & 25198 & & $13.8 \pm 0.16$ & $6.4 \pm 0.01$ \\
M. D. & 25105 & & $13.8 \pm 0.12$ & $6.3 \pm 0.05$ \\
R. M. & 25314 & & $13.5 \pm 0.12$ & $5.8 \pm 0.05$ \\
Average & & 12.9 & 13.9 & 7.2 \\
\hline
\end{tabular}

* Standard error of mean. 
THIOURACIL WITH IODINE IN GRAVES' DISEASE

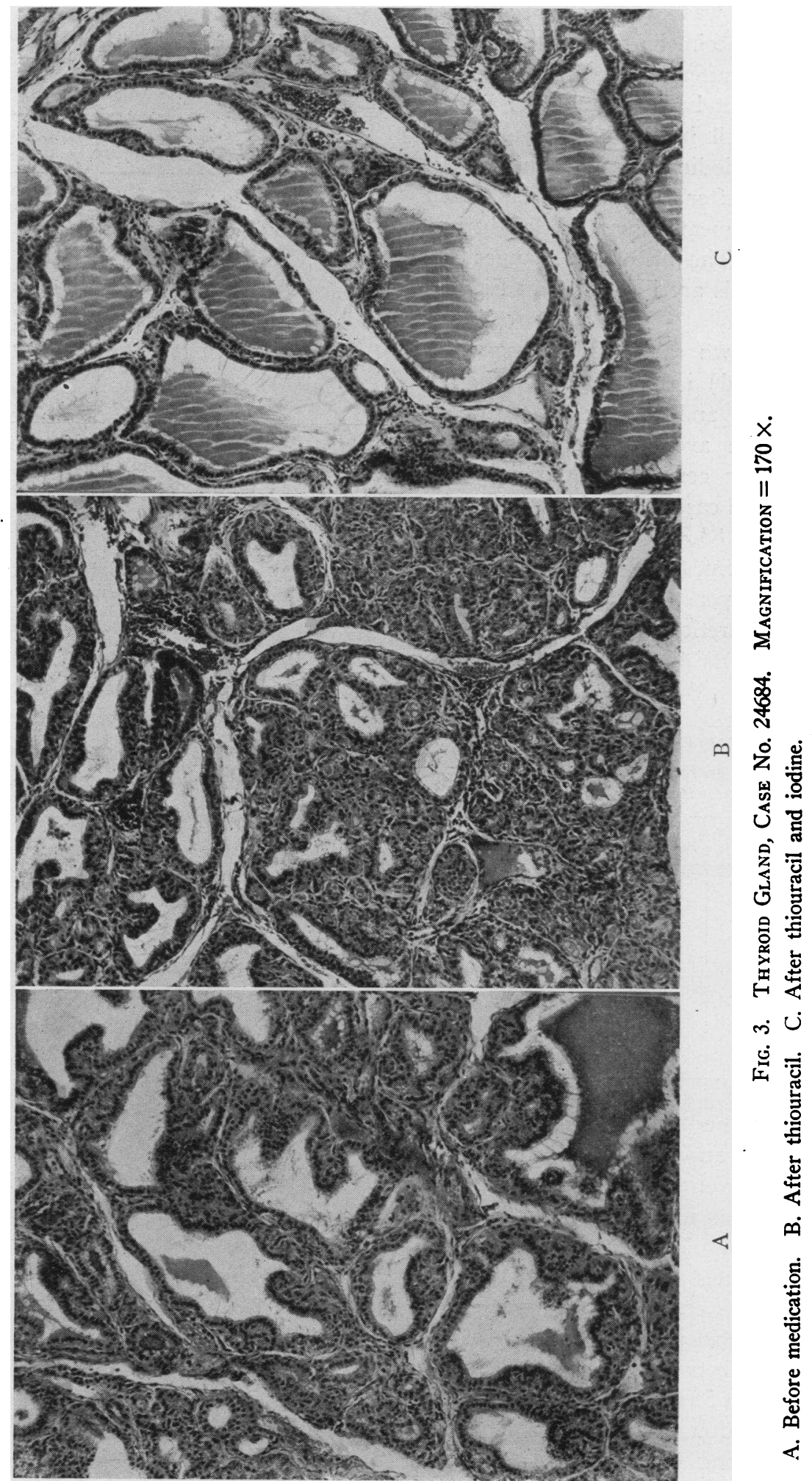


before any treatment was given, an average of 13.2 micra. In the specimens removed at biopsy in these same 4 cases, after thiouracil, the average mean acinar cell height had risen to 14.1 micra. The average mean cell height in 7 cases after thiouracil, but before iodine was 13.9 micra. In these same 7 cases after both drugs had been exhibited the average mean acinar cell height had fallen to 7.2 micra. The histologic changes observed in these thyroids are illustrated in Figures 1 to 3 .

In Table II are shown values for the excretion of radioactive (labelled) iodine in 3 cases before any drug was given, and in 6 after treatment with thiouracil. The average excretion before thiouracil was 25 per cent of the administered dose. In these same 3 cases after thiouracil treatment, it had risen to 83.7 per cent. In 6 cases after thiouracil treatment, the average radio iodine excretion was 80.3 per cent. This increased radioactive iodine excretion in the thiouracilized patient strongly suggests diminished utilization in the gland.

TABLE II

Radioactive iodine excretion before and after thiouracil treatment

\begin{tabular}{c|c|c|c}
\hline \hline Patient & Lab. no. & Before treatment & After treatment \\
\cline { 3 - 4 } & & per cent & per cent \\
C. T. & 24972 & 12.7 & 94.5 \\
A. H. & 25234 & 46.0 & 83.2 \\
A. S. & 24684 & 16.3 & 73.5 \\
R. M. & 25314 & & 93.0 \\
E. L. & 25198 & & 61.0 \\
M. D. & 25101 & & 76.6 \\
Average & & & 80.3 \\
\hline
\end{tabular}

The iodine content and distribution in the thyroids removed at operation, after both drugs had been exhibited, is given in Table III. These values are calculated as milligrams of iodine per 100 grams of fresh thyroid tissue.

The total iodine values obtained varied between 6.4 and 41.3 with an average of $22.1 \mathrm{mgm}$. The iodine values of the acid precipitate of digests of these tissues varied between 1.1 and 18.5 and averaged $7.0 \mathrm{mgm}$. In 5 cases the iodine values of digests of the tissue after dialysis varied between 1.4 and 21.8 , averaging $8.3 \mathrm{mgm}$. The thyroglobulin iodine values here are very low. The significance of these low thyroglobulin iodine
TABLE III

Iodine values of thyroids removed at operation

\begin{tabular}{|c|c|c|c|c|}
\hline \multirow{2}{*}{ Patient } & \multirow{2}{*}{ Lab. no. } & \multicolumn{3}{|c|}{ Fresh tissue } \\
\hline & & $\begin{array}{l}\text { Tota! } \\
\text { iodine }\end{array}$ & $\begin{array}{c}\text { Thyroglobulin } \\
\text { iodine }\end{array}$ & $\begin{array}{c}\text { Non-dialysable } \\
\text { iodine }\end{array}$ \\
\hline & & $\begin{array}{l}\text { mgm. per } \\
100 \text { grams }\end{array}$ & $\begin{array}{l}\text { mgm. per } \\
100 \text { grams }\end{array}$ & $\begin{array}{l}\text { mgm. per } \\
100 \text { grams }\end{array}$ \\
\hline C. T. & 24972 & 6.4 & 1.2 & \\
\hline H. M. & 25097 & 10.9 & 7.4 & 1.4 \\
\hline A. H. & 25234 & & 1.1 & \\
\hline A. S. & 24684 & 24.7 & 2.3 & 2.9 \\
\hline E. L. & 25198 & 26.2 & 6.5 & $10.7^{*}$ \\
\hline M. D. & 25105 & 41.3 & 18.5 & $21.8 \dagger$ \\
\hline R. M. & 25314 & 23.4 & 12.2 & $5.0 \ddagger$ \\
\hline Average & & 22.1 & 7.0 & 8.3 \\
\hline
\end{tabular}

* Had taken iodine for 3 months until 3 months before thiouracil was administered.

† Received 1 dose of iodine when theoretically free of thiouracil effect (see text).

$\ddagger$ Had taken iodine for 5 months until 1 month before thiouracil was administered.

values becomes more impressive when compared with the values obtained by the same techniques on normal human thyroids, thyroids removed from thyrotoxic patients treated with iodine alone and on thyroids removed from thyrotoxic patients after treatment with thiouracil alone. The total and thyroglobulin iodine values determined on a small series of normal human thyroids averaged 67.2 and $29.8 \mathrm{mgm}$. per 100 grams of fresh thyroid tissue respectively. The thyroids of another small series of thyrotoxic patients removed after an adequate response to iodine therapy had averaged total and thyroglobulin iodine values of 50.8 and $36.6 \mathrm{mgm}$. per 100 grams of fresh thyroid tissue respectively. The total thyroid iodine of 4 thyrotoxic patients whose thyroids were removed after thiouracil alone varied between 2.95 and 30.4 and averaged $18.8 \mathrm{mgm}$. The thyroglobulin iodine values obtained on these same glands ranged between 1.07 and 11.8 and averaged $6.82 \mathrm{mgm}$. per 100 grams of fresh tissue. The thyroglobulin values obtained on this latter group of patients are comparable to the values obtained in our study of patients after treatment with thiouracil and iodine together.

In comparing the iodine values on these thyroids, it is of interest to point out that patients E. L., No. 25198, and R. M., No. 25314, had received iodine for periods of 3 to 5 months until 3 to 1 months respectively before thiouracil treatmen had been begun, and that the somewhat 
higher thyroglobulin and non-dialysable iodine levels observed in their glands might be accounted for on that basis. M. D., No. 25105, gave no history of having taken iodine previous to her entry which might account for the elevated total thyroglobulin and non-dialysable iodine levels observed in her thyroid. However, on the day that the biopsy was taken from her thyroid she received 0.2 gram of thiouracil at 6 a.m. and none again until 10 p.m. of the same day. At 6 p.m. of that day she received $330 \mathrm{mgm}$. of potassium iodide. It has been demonstrated (14) that a 0.2 -gram dose of thiouracil is practically all excreted in 8 hours. It has also been demonstrated (13) that the block to the collection of iodine produced by thiouracil lasts only between 6 and 12 hours. It would seem quite likely then that the higher level of thyroid iodine observed in this patient's tissue was due to the administration of iodine when the patient's thyroid was free of any thiouracil effect.

The urinary excretion of the labelled iodine given A. S., No. 24684, is represented graphically in Figure 4. It will be observed that this patient excreted only 16.3 per cent of a tracer dose of

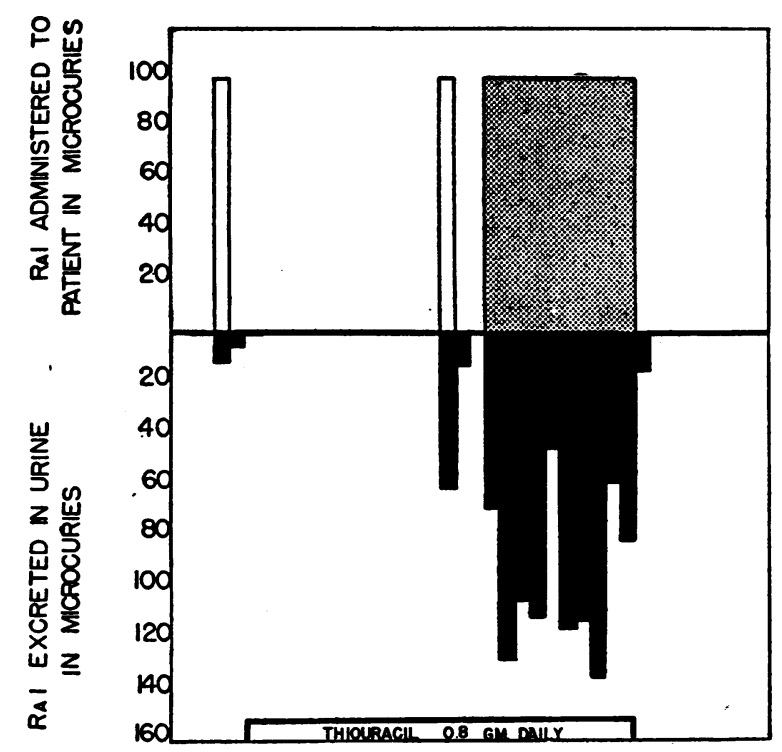

Fig. 4. Radio-iodine Balance in Case No. 24684

Intake above the line. Urinary excretion below. With regard to intake plain columns indicate that tracer iodine was given with carrier of 150 gamma of ordinary sodium iodide. Stippled columns indicate that tracer iodine was given with carrier of $300 \mathrm{mgms}$. daily of ordinary sodium iodine. The latter carrier amounted to a therapeutic dose of ordinary iodine. (See text.) iodine given 48 hours before her pre-treatment biopsy was taken. After she had received thiouracil, 0.8 gram daily for 15 days, she excreted 73.5 per cent of a similar tracer of radioactive iodine. Following the second biopsy taken from her thyroid, all of the iodine which she received was labelled with 100 microcuries of radioactive iodine daily. The radioactivity demonstrated in the excreted urine during and after the 10-day period of treatment with thiouracil and labelled iodine, practically equalled the radioactivity administered. Indeed, when it is totalled, 104 per cent of the administered radioactive iodine was demonstrable in the urine. The radioactivity demonstrated in the operatively removed thyroid was reported as being too little to measure.

\section{DISCUSSION}

From the observations made in this study it becomes quite apparent that the iodinating action can be separated from the involuting action of iodine on the thyroid, inasmuch as thiouracilized patients exhibit the involuting action without iodination of the hormone.

It has been stated by Harington (15) that "the first event in the synthesis of thyroxine by the thyroid gland must be substitution of the iodine in the molecule of an organic compound and such substitution can only occur after oxidation of the iodide." It has been reported (16) with in vitro experiments that thiouracil inhibits peroxidase activity in the thyroid and that this diminished peroxidase activity would interfere with the conversion of diiodotyrosine to thyroxine. Since it has been amply demonstrated in previous studies that thiouracil will prevent the concentration of iodine in the thyroid, and in these studies that it will interfere with the iodination of thyroid protein, it might be suggested that the enzyme which had been found to be inhibited has as a primary function the oxidation of iodide to iodine.

Whether it be peroxidase which has to do with the iodination of the thyroid protein or some other enzyme, the evidence from these observations would indicate that iodine when administered in doses of 300 or more mgm. daily to adequately thiouracilized patients is inutile for the iodination or synthesis of thyroid hormone. However, notwithstanding this barrier to the production and 
storage of a normally iodinated thyroid hormone, the administration of iodine to a patient having Graves' disease causes involution of the hyperplastic thyroid so characteristic of that malady.

These observations make untenable the theory (1) that iodine causes detoxication of the patient with Graves' disease by bringing about complete iodination of the hormone molecule. Likewise, the theory (8) that "the effect of iodine therapy is to favor the synthesis and deposition of hormone rather than its release" will require modification. It is true that the administration of iodine to a thyrotoxic patient will promote the storage of thyroid hormone. However as our observations demonstrate, involution of the thyroid is not dependent upon the deposition of hormone. A more tenable explanation would be that the storage of thyroglobulin results from the inhibition of some process which has to do with the increased rate of secretion of thyroid hormone. It has been demonstrated (17) that the 2 earliest effects on the thyroid produced by the administration of thyrotropic hormone are an increase in the mean acinar cell height and a loss of stored iodine. An increase in the rate of collection of iodine was not observed until later. Removal of thyrotropic stimulation or inhibition of this hormone's action should result then in involution of the hypertrophied thyroid cell and in a cessation of increased secretion of hormone. The apparent increased deposition of thyroid hormone could then be due to a block in the delivery of hormone (4).

In 1941, it was reported that explants of thyroid tissue, when bathed in a medium containing pituitary extract, inactivate the thyrotropic hormone, whereas explants of other tissues, excepting thymus and lymph nodes, have no effect on the thyrotropic hormone exposed to them (18). On the basis of these observations, we have thought that the thyrotropic hormone in exerting its action on its endorgan is inactivated possibly by combining with some substance in the thyroid or by contributing some essential part of its molecule to the metabolism of the thyroid cell. In another series (19) of in vitro studies, we have observed that the inactivation of thyrotropic hormone contained in the bathing medium upon exposure to explants of thyroid tissue slices was almost completely inhibited if iodide was contained in the medium. These observations would indicate then that iodine exerts its involuting effect in Graves' disease by inhibiting the action of the thyrotropic hormone. A major criticism to the theory that the involuting action of iodine is brought about by inhibiting the action of thyrotropic hormone on the thyroid is that iodine, when administered to normal individuals, has not been observed to cause any clinical hypothyroidism. Indeed, its administration to patients with Graves' disease only rarely causes a state of hypothyroidism.

On the other hand, it might be pointed out that in another in vitro study it was observed (20) that explants of tissue slices taken from thyroids of patients with Graves' disease inactivated about twice as much thyrotropic hormone as did similar explanted slices taken from normal human thyroids. It may be suggested then that iodine, when administered to patients with Graves' disease, acts by inhibiting an increased sensitivity of the thyroid cell to the action of thyrotropic hormone and that since this increased sensivitity to thyrotropic hormone does not exist in normal human thyroids, the action of iodine in these people does not cause any dramatic effect.

\section{SUM MARY}

Patients with Graves' disease have been studied before any medication was given, after treatment with thiouracil had caused a fall in the basal metabolic rate to a standard level and after receiving both thiouracil and iodine. Observations have included microhistometric studies of biopsy specimens taken before either drug, after thiouracil treatment, but before iodine, and of glands removed at operation after treatment with both drugs.

Urinary excretion of radioactive iodine was determined before and during thiouracil treatment. Total and bound iodines were determined in the operatively removed thyroids.

The results show hyperplasia due to the disease before thiouracil,-average mean thyroid cell height 12.9 micra ; and a greater degree of hyperplasia after thiouracil,-average mean acinar cell height 13.9 micra. However, involution was observed after iodine had been administered in addition to thiouracil, mean cell height 7.2 micra.

Before treatment with thiouracil the excretion of radioactive iodine averaged 25 per cent. Dur- 
ing thiouracil treatment, the average excretion of radioactive iodine was 80 per cent.

The iodine values of thyroids removed at operation averaged for total iodine $22.1 \mathrm{mgm}$. per 100 grams of fresh thyroid tissue, and for thyroglobulin iodine $7.0 \mathrm{mgm}$. per 100 grams of fresh tissue. These values are comparable to the values obtained from the thyroids of thyrotoxic patients removed after treatment with thiouracil only.

\section{CONCLUSIONS}

It appears (1) that under thiouracil treatment the hyperplastic thyroid gland of Graves' disease becomes yet more hyperplastic, (2) that thiouracil prevents the utilization of iodine by the thyroid, (3) that notwithstanding this block to the collection of iodine produced by thiouracil, iodine causes involution of the thyroid gland in Graves' disease.

Therefore, it is concluded that iodine exerts 2 actions upon the thyroid gland in Graves' disease, an iodinating action and an involuting action, and that these 2 actions can be separated one from the other by means of thiouracil.

\section{BIBLIOGRAPHY}

1. Plummer, H. S., Results of administering iodine to patients having exophthalmic goiter. J. A. M. A., 1923, 80, 1955.

2. Means, J. H., and Richardson, E. P., Diseases of the Thyroid. Oxford University Press. New York, 1929, p. 152.

3. Thompson, W. O., Brailey, A. G., Thompson, P. K., and Thorp, E. G., The range of effective iodine dosage in exophthalmic goiter. The effect on basal metabolism of rest and of the daily administration of one drop of compound solution of iodine. Arch. Int. Med., 1930, 45, 261.

4. Means, J. H., and Lerman, J., The action of iodine in thyrotoxicosis. J. A. M. A., 1935, 104, 969.

5. Gutman, A. B., Benedict, E. M., Baxter, B., and Palmer, W. W., The effect of administration of iodine on the total iodine and thyroxine content of the pathological thyroid gland. J. Biol. Chem., 1932, 97, 303.

6. Loeser, A., and Thompson, K. W., Hypophysenvorderlappen, Jod und Schilddruese. Endokrinologie, 1934, 14, 144.

7. Friedgood, H. B., Similarity of the iodin remission in experimental anterior hypophyseal hyperthyroidism, the hyperthyroidism of acromegaly and that of exophthalmic goiter. Endocrinology, 1936, 20, 526.

8. Salter, W. T., and Lerman, J., The genesis of thyroid protein: clinical assays of artificial thyroid protein in human myxedema. Endocrinology, 1936, 20, 801.

9. Salter, W. T., The Endocrine Function of Iodine. Harvard University Press, Cambridge, Mass., 1940, p. 120.

10. Rawson, R. W., Evans, R. D., Means, J. H., Peacock, W. C., Lerman, J., and Cortell, R. E., The action of thiouracil upon the thyroid gland in Graves' disease. J. Clin. Endocrinol., 1944, 4, 1.

11. Astwood, E. B., and Bissell, A., Effect of thiouracil on the iodine content of the thyroid gland. Endocrinology, 1944, 34, 282.

12. Rawson, R. W., Tannheimer, J. F., and Peacock, W., The uptake of radioactive iodine by the thyroids of rats made goiterous by potassium thiocyanate and by thiouracil. Endocrinology, 1944, 34, 245.

13. Larson, R., Keating, F. R., Peacock, W., and Rawson, R. W., The effect of thiouracil on the collection of radioactive iodine by the thyroid of the chick. Endocrinology, 1945, 36, 160.

14. Williams, R. H., Kay, G. A., and Jandorf, B. J., Thiouracil, its absorption, distribution and excretion. J. Clin. Invest., 1944, 23, 613.

15. Harington, C. R., Newer knowledge of the biochemistry of the thyroid gland. Jr. Chem. Society, 1944, 193.

16. Dempsey, E. W., Fluorescent and histochemical reactions in the rat thyroid gland at different states of physiological activity. Endocrinology, 1944, 34, 27.

17. Keating, F. R., Rawson, R. W., Peacock, W., and Evans, R. D., The collection and loss of radioactive iodine compared with the anatomic changes induced in the thyroid of the chick by the injection of thyrotropic hormone. Endocrinology, 1945, 36, 137.

18. Rawson, R. W., Sterne, G. D., and Aub, J. C., Physiological reactions of the thyroid-stimulating hormone of the pituitary. I. Its inactivation by exposure to thyroid tissue in vitro. Endocrinology, 1942, 30, 240.

19. Rawson, R. W., McArthur, J. W., Riddell, C. B., and Lennon, B. E., Physiological reactions of the thyroid stimulating hormone of the pituitary. III. The effect of iodide on its inactivation by exposure to thyroid tissue in vitro. Unpublished.

20. Rawson, R. W., Graham, R. M., and Riddell, C. B., Physiological reactions of the thyroid stimulating hormone of the pituitary. II. The effect of normal and pathological human thyroid tissues on the activity of the thyroid stimulating hormone. Ann. Int. Med., 1943, 19, 405. 